\title{
Knowledge and practice of feeding plate obturators among medical doctors in Kanti children's hospital
}

\author{
Pathak B ${ }^{1}$, Joshi $\mathrm{KR}^{2}$, Bhattarai $\mathrm{S}^{3}$, Joshi $\mathrm{H}^{4}$ \\ ${ }^{1}$ Lecturer, Department of Prosthodontics, CODS-Nepal Medical College, Kathmandu Nepal \\ ${ }^{2}$ Consultant Pediatric Dentist, Kanti Children's Hospital, Kathmandu, Nepal \\ ${ }^{3,4}$ Pediatrician, Kanti Children's Hospital, Kathmandu, Nepal
}

\begin{abstract}
Introduction: Cleft lip and cleft palate (CLCP) affects several systems and functions of the child and result in social and psychological problems.Therefore early repair of CLCP is imperative. Every cleft center follows its own surgical treatment protocol. Before closure of palatal defects, babies with cleft palate have great difficulty in feeding. To overcome this feeding difficulties, use of special bottles, nipples, initial palatal obturator therapy are used. The first exposure of those children are primarily the medical doctors including pediatricians from where they are generally referred to the concerned speciality for repair of CLCP. The aim of this study was to assess the knowledge and practice of orofacial clefts and feeding plate obturator among medical doctors working in Kanti Children's Hospital (KCH). Method: This was a questionnaire based survey among medical doctors working in $\mathrm{KCH}$. The pretested questionnaire with 7 questions each on the knowledge and practice of feeding plate obturators was distributed among the medical doctors and data was collected. The data collected were subjected to statistical analysis using frequency of responses and percentages.

Results: Of the total 57 study participants, 32 (56.1\%) were males and $25(43.9 \%)$ were females. Majority i.e. $61.4 \%$ belonged to $31-40$ years age group. $91.2 \%$ study participants faced the cleft lip/ palate related feeding difficulties $0-5$ times/month while 5 (8.8\%) faced this condition 6-10 times/ month. Majority of the infants who were less than 28 days (43.9\%) attended the OPD due to difficulty in feeding/ swallowing (57.9\%) followed by regurgitation/aspiration (22.8\%). 49.1\% of the participants thought feeding plate oburator as the best way to feed a cleft patient on discharge from hospital. In their clinical practice, three fourth of paticipants $(70.2 \%)$ had never seen a patient with feeding plate obturator, half of the participants $(50.9 \%)$ didn't advise for feeding plate obturator for patients with cleft palate and $89.5 \%$ were not aware of the replacement of feeding plate obturator.

Conclusion: There is low exposure regarding the feeding plate obturator among medical doctors in $\mathrm{KCH}$ which needs to be reinforced through meaningful continuing education and training programs.
\end{abstract}

Key words: cleft surgery; feeding difficulty; feeding plate obturator; orofacial cleft.

\section{Introduction}

$\mathrm{T}$ he orofacial clefts fall into a common group of congenital malformations seen

\section{Conflict of Interest: No}

\section{*Corresponding Author}

Dr. Binita Pathak, Lecturer

Department of Prosthodontics

CODS-Nepal Medical College, Kathmandu, Nepal

E-mail:drbinitapathak@gmail.com with a very high incidence. ${ }^{1}$ Its consequences affect several systems and functions of the child and result in social and psychological problems. Therefore, early repair of clefts is imperative. ${ }^{2}$ The optimal timing for cleft palate surgery still remains controversial. ${ }^{3}$

Neonates with a cleft palate have difficulty in feeding which may lead to failure to thrive. ${ }^{4}$ Degree of feeding difficulty varies with the type and severity of the cleft..$^{5}$ Inefficient oral 
feeding results in retardation of growth and development. ${ }^{6,7}$ Their repair surgery is usually postponed because of not gaining weight properly and they get admitted multiple times with recurrent aspiration pneumonia and other comorbidities. Feeding obturator promotes neonatal weight gain, which is important in preparing the baby for corrective surgery. ${ }^{8} \mathrm{~A}$ feeding plate obturator is a prosthesis inserted into mouth over the hard palate so as to separate the nasal and oral cavity. ${ }^{2}$ But many patients aren't given this option probably due to lack of the knowledge of feeding plate obturators among attending doctors. Till now no survey has been undertaken to assess the knowledge and practice of Medical doctors regarding the use of feeding plate obturator for the management of infants with CLCP in Nepal.

This study aimed to assess the knowledge and practice of attending medical doctor regarding orofacial cleft and their management with feeding plate obturator.

\section{Materials and Method}

This Cross-sectional questionnaire based survey was conducted among all the medical doctors working in Kanti Children's Hospital $(\mathrm{KCH})$, Maharajgunj. Ethical approval was taken from the Ethical Review Committee, $\mathrm{KCH}$ before commencement of study (IRC Protocol Reg No. 41/2020/021). The data collection tool was structured questionnaire which was adopted from a previous study ${ }^{9}$ and some questions were modified by authors after consultation with the experts related to field. The questionnaire was pre-tested to check the validity and reliability. The pre-testing of paper-based questionnaire was done by running a pilot test on 10 medical doctors working in other hospitals who were not included in this study.

The questionnaire consisted of three sections. The first section included demographics of participants, second section had seven questions designed to assess the knowledge of medical doctors about the orofacial clefts, its management protocol and third section had seven questions related to the practice of medical doctors ragarding use of feeding plate obturator for management of cleft patients.

The study was conducted in the month of March-April 2021. The printed questionnaire along with informed consent were distributed among the Paediatricians, Pediatric Residents and Medical Officers working in $\mathrm{KCH}$. All the participants were informed about the aims and objectives of the study. Partcipants who signed informed consent form were included in the study. Adequate time was provided to fill the questionnaire.

The response of the practitioners were recorded, analysed for flaws, checked for completeness and were manually coded and entered into Microsoft Excel sheet, then data was analyzed with SPSS version 16 and were subjected to statistical analysis using frequency of responses and percentages.

\section{Results}

Questionnaires were distributed among 85 medical doctors and 57 of them gave the consent and filled the form with a positive response rate of $67.05 \%$.

\section{Socio-demographic characteristics}

Of the total 57 study participants, $32(56.1 \%)$ were males and $25(43.9 \%)$ were females (Figure 1). Majority i.e. $61.4 \%$ belonged to 31-40 years age group (Figure 2).

Out of the total, 52 i.e. $91.2 \%$ study participants faced the cleft lip/ palate related feeding difficulties $0-5$ times/ month while $5(8.8 \%)$ faced this condition 6-10 times/ month. Majority of the infants attended the OPD due to difficulty in feeding/ swallowing (57.9\%) followed by regurgitation/ aspiration (22.8\%) as in Figure 3. 
The most common age group of children that approached in need of treatment with cleft lip/ palate were less than 28 days $(43.9 \%)$ followed by $1-3$ months $(29.8 \%)$ as in Figure 4.

The responses for knowledge related questions have been shown in Table 2. 71.9\% of study participants thought that cleft lip and palate is multifactorial (environmental, genectic and medications during pregnancy). Out of total, $73.7 \%$ of participants thought that multidisciplinary team which includes various specialists such as pediatrician, plastic surgeon, pediatric dentist, otolaryngologist, geneticist, genetic counselor, speech pathologist, orthodontist, prosthodontist, maxillofacial surgeon, psychologist, and nursing team is needed to treat patients with CLCP. Majority of participants(98.2\%) mentioned that the surgical intervention, nutritional management and speech therapy combined is the treatment modalities for cleft.

Table 4 describes the practice related responses. Almost three fourth (70.2\%) of participants had never seen a cleft patient with feeding plate obturator. Half of the participants (50.9\%) didn't advise for feeding plate obturator for patients with cleft palate and $89.5 \%$ were not aware of the replacement of feeding plate obturator.

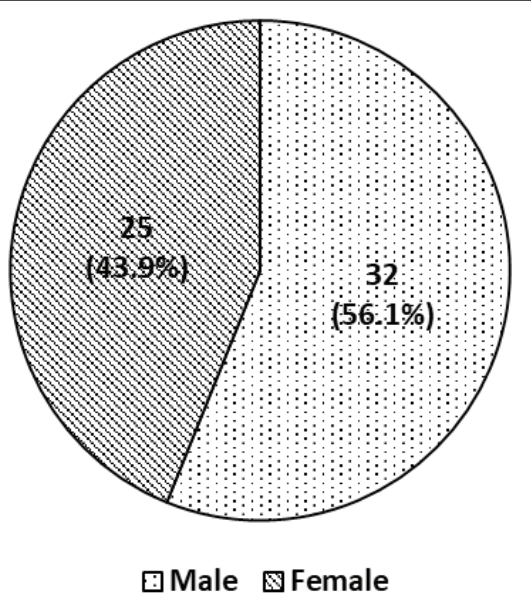

Figure 1: Gender wise distribution of study participants

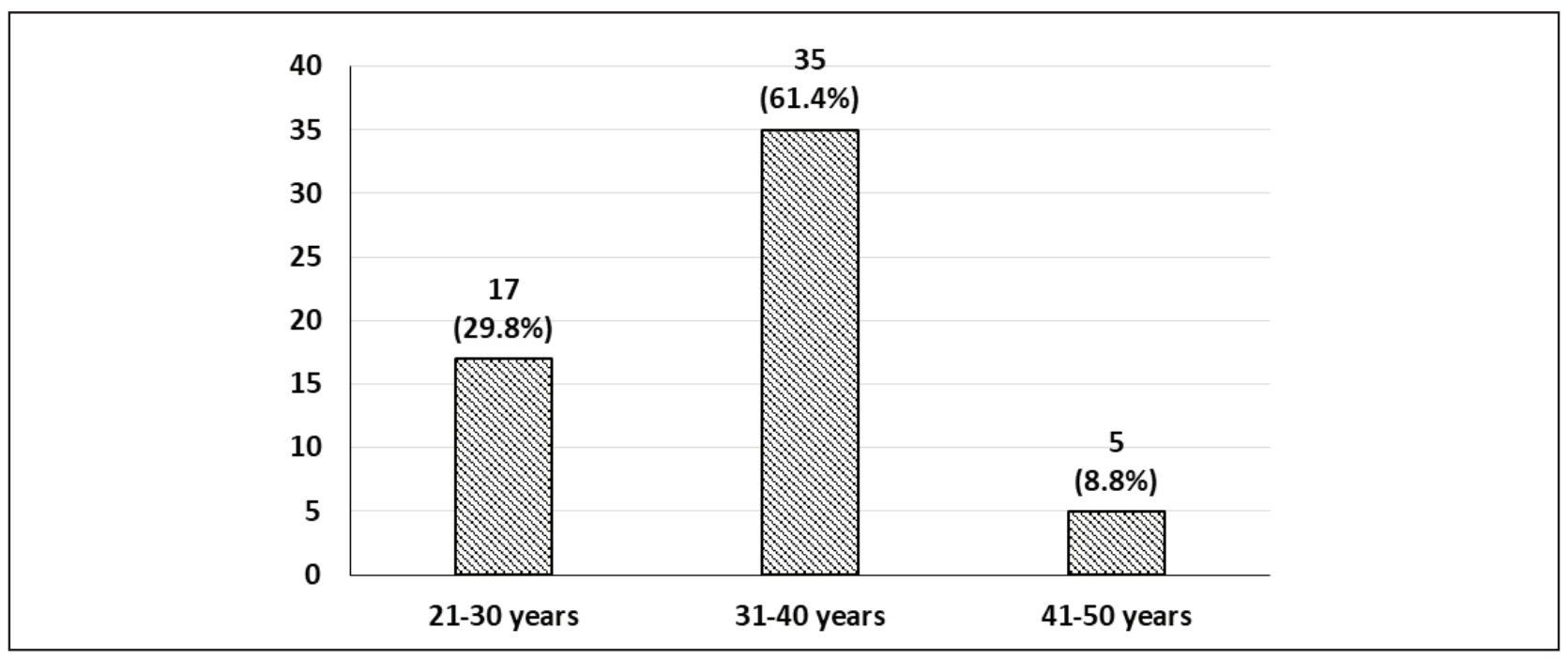

Figure 2: Distribution of study participants according to age groups 


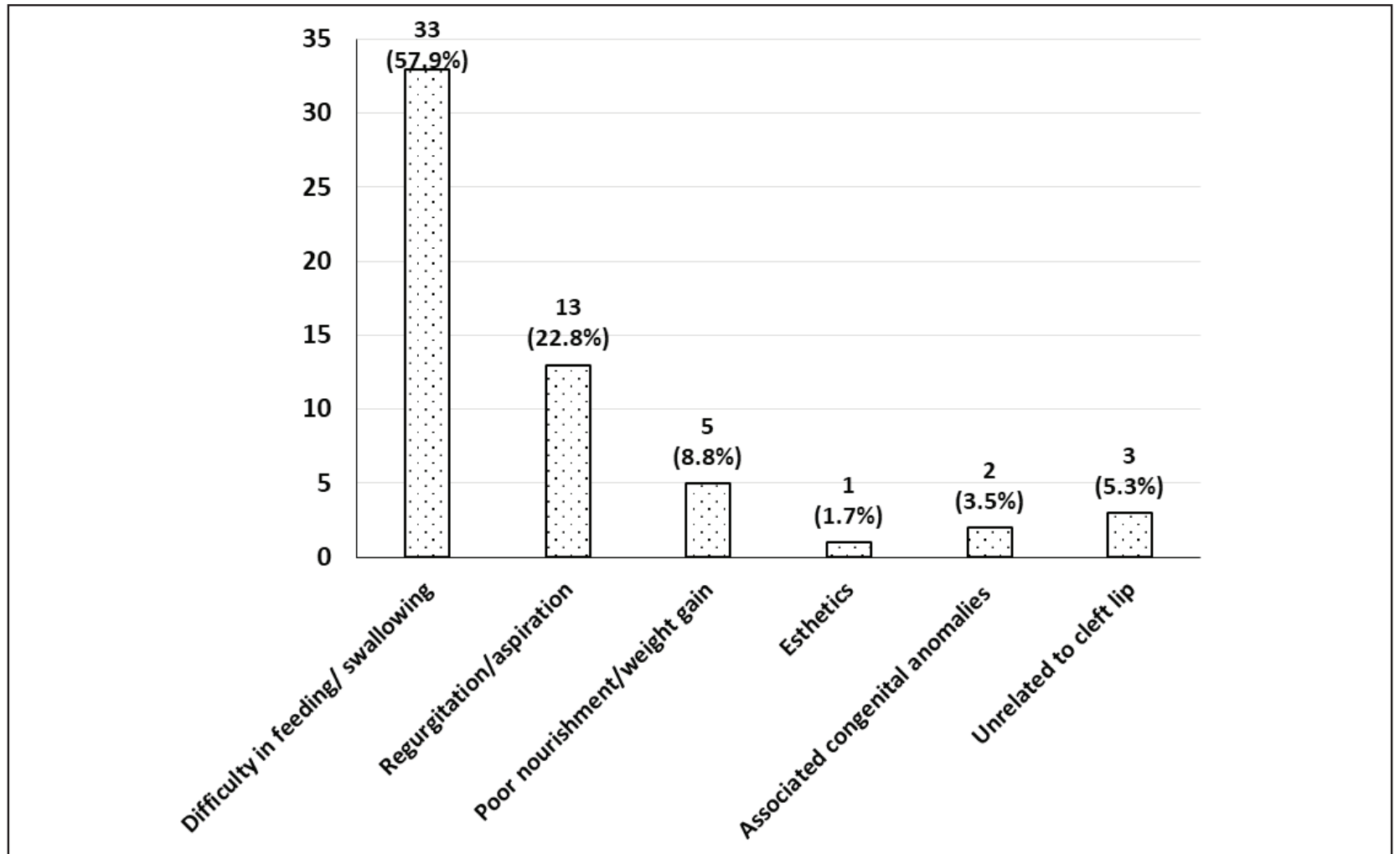

Figure 3: Responses regarding the primary cause of the infants attending the OPD

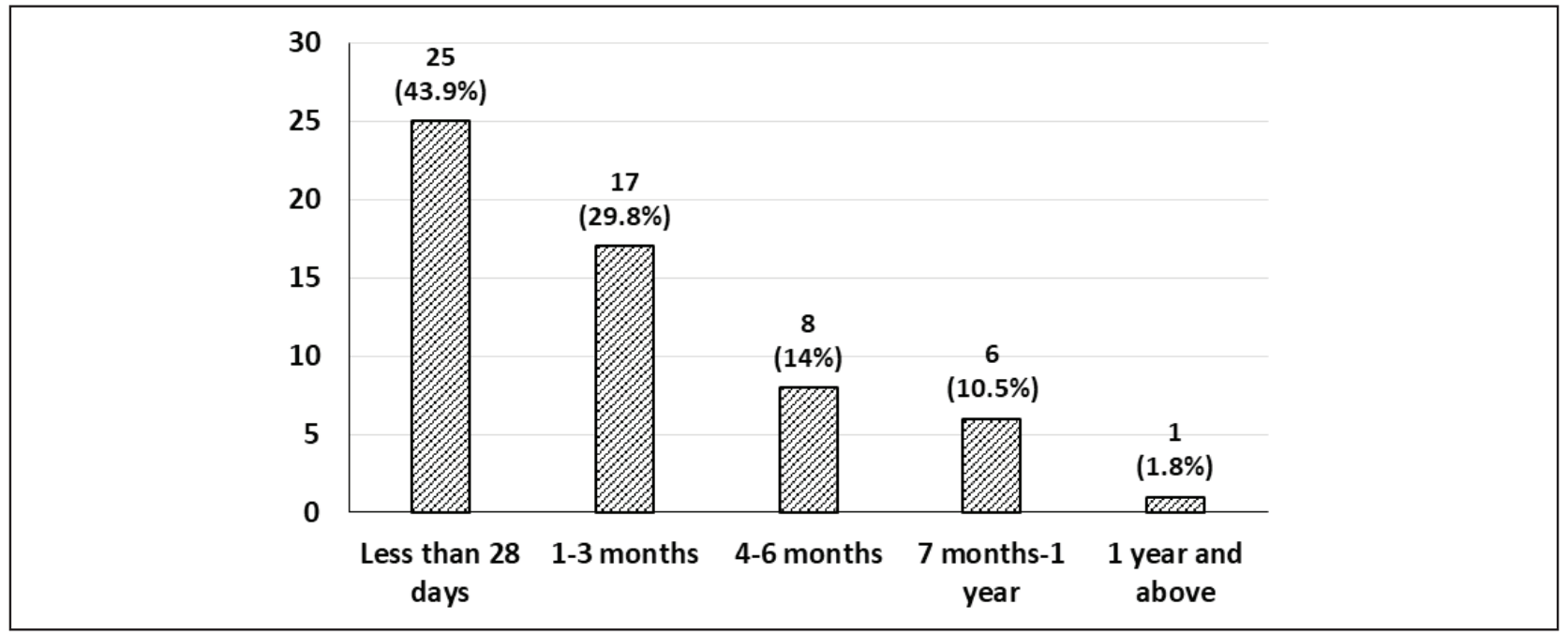

Figure 4: Responses regarding the most common age group of children that approached in need of treatment

Table 1: Distribution of the study participants according to highest qualification and experience

\begin{tabular}{|l|c|c|}
\hline Variables & & $\mathbf{n ~ ( \% )}$ \\
\hline \multirow{4}{*}{ Highest qualification } & MBBS & $7(12.3)$ \\
\cline { 2 - 3 } & MD/ MS & $28(49.1)$ \\
\cline { 2 - 3 } & Resident & $21(36.8)$ \\
\cline { 2 - 3 } Years of experience & Fellowship/ DM & $1(1.8)$ \\
& $1-5$ years & $34(59.6)$ \\
\hline Total & $6-10$ years & $18(31.6)$ \\
\hline
\end{tabular}


Table 2: Knowledge related responses among the study participants

\begin{tabular}{|c|c|c|}
\hline & Responses & $\mathrm{n}(\%)$ \\
\hline \multirow{4}{*}{ What is the primary cause of cleft lip/palate? } & Genetic & $15(26.3 \%)$ \\
\hline & Environmental & - \\
\hline & $\begin{array}{l}\text { Medication during } \\
\text { pregnancy }\end{array}$ & $1(1.8 \%)$ \\
\hline & All of the above & $41(71.9 \%)$ \\
\hline \multirow{12}{*}{$\begin{array}{l}\text { Who are all the concerned clinicians in the team for } \\
\text { multidisciplinary treatment of a child with an orofacial cleft? }\end{array}$} & Pediatrician & $12(21.1 \%)$ \\
\hline & Plastic surgeon & $12(21.1 \%)$ \\
\hline & Pediatric dentist & $6(10.5 \%)$ \\
\hline & Otolaryngologist & $8(14 \%)$ \\
\hline & Geneticist & $2(3.5 \%)$ \\
\hline & Genetic counselor & $1(1.8 \%)$ \\
\hline & Speech pathologist & $3(5.3 \%)$ \\
\hline & Orthodontist & - \\
\hline & Prosthodontist & - \\
\hline & Maxillofacial surgeon & $7(12.3 \%)$ \\
\hline & Psychologist & $1(1.8 \%)$ \\
\hline & All of the above & $42(73.7 \%)$ \\
\hline \multirow{4}{*}{ What are all the treatment modalities for a cleft patient? } & Surgical intervention & $1(1.8 \%)$ \\
\hline & Speech therapy & - \\
\hline & Nutritional management & - \\
\hline & All of the above & $56(98.2 \%)$ \\
\hline \multirow{4}{*}{$\begin{array}{l}\text { What is the best way a patient with cleft palate be fed on } \\
\text { discharge from hospital? }\end{array}$} & Modified Nipple & $2(3.5 \%)$ \\
\hline & Feeding plate obturator & $28(49.1 \%)$ \\
\hline & NG/OG tube feeding & $4(7 \%)$ \\
\hline & All of the above & $23(40.4 \%)$ \\
\hline \multirow{4}{*}{$\begin{array}{l}\text { What is the ideal age for soft Palate Repair/closure in two } \\
\text { stage closure? }\end{array}$} & As soon as possible & $6(10.5 \%)$ \\
\hline & 3-6 months & $17(29.8 \%)$ \\
\hline & $9-12$ months & $26(45.7 \%)$ \\
\hline & 15-18 months & $8(14 \%)$ \\
\hline \multirow{4}{*}{$\begin{array}{l}\text { What is the ideal age for Hard palate repair/closure in two } \\
\text { stage closure? }\end{array}$} & As soon as possible & $3(5.3 \%)$ \\
\hline & 3-6 months & $5(8.8 \%)$ \\
\hline & 10 months & $21(36.8 \%)$ \\
\hline & $15-18$ months & $28(49.1 \%)$ \\
\hline \multirow{4}{*}{$\begin{array}{l}\text { What is the ultimate goal of the management of child with } \\
\text { cleft palate? }\end{array}$} & Normal speech & $5(8.8 \%)$ \\
\hline & Maxillofacial growth & $4(7 \%)$ \\
\hline & Hearing & - \\
\hline & All of the above & $48(84.2 \%)$ \\
\hline
\end{tabular}

Table 3: Practice related responses among the study participants

\begin{tabular}{|l|l|c|}
\hline Questions & Responses & n (\%) \\
\hline \multirow{4}{*}{$\begin{array}{l}\text { Where do you primarily send the patients for further } \\
\text { management after treating the primary ailment? }\end{array}$} & Maxillofacial Surgeon & $39(68.4)$ \\
\cline { 2 - 3 } & ENT surgeons & $7(12.3)$ \\
\cline { 2 - 3 } & Prosthodontist & $9(15.8)$ \\
\cline { 2 - 3 } & Dietician & $3(5.3)$ \\
\cline { 2 - 3 } & Speech Therapist & $3(10.5)$ \\
\cline { 2 - 3 } & Orthodontist & $3(5.3)$ \\
\hline
\end{tabular}


Please tick all those sub-specialties where you send these patients for further management?
Have you seen a patient with feeding plate obturator?

Do you advise/refer for the feeding plate obturator for patients with cleft palate in your practice? Have you ever helped the dentist in making impression of cleft palate for feeding plate fabrication?

How frequently do you advise feeding plate obturator to be replaced/fabricated?

7. How often have you felt that fabrication of feeding plate helps in reducing the anxiety levels of mothers of infants with orofacial clefts during feeding?

\begin{tabular}{|l|c|}
\hline Pediatrician & $9(15.8)$ \\
\hline Plastic surgeon & $14(24.6)$ \\
\hline Pediatric dentist & $10(17.5)$ \\
\hline Otolaryngologist & $8(14)$ \\
\hline Geneticist & $1(1.8)$ \\
\hline Genetic counselor & $2(3.5)$ \\
\hline Speech pathologist & $7(12.3)$ \\
\hline Orthodontist & $3(5.3)$ \\
\hline Prosthodontist & $4(7)$ \\
\hline Maxillofacial surgeon & $11(19.3)$ \\
\hline Psychologist & $7(12.3)$ \\
\hline All of the above & $35(61.4)$ \\
\hline Yes & $17(29.8)$ \\
\hline No & $40(70.2)$ \\
\hline Yes & $28(49.1)$ \\
\hline No & $29(50.9)$ \\
\hline Yes & $3(5.3)$ \\
\hline No & $54(94.7)$ \\
\hline Just once & - \\
\hline Every month & $2(3.5)$ \\
\hline every 2-3 months & $4(7)$ \\
\hline I don't know & $51(89.5)$ \\
\hline Reduced anxiety in all the mothers & $3(5.3)$ \\
\hline $\begin{array}{l}\text { Reduced the anxiety, but not for } \\
\text { all of them }\end{array}$ & $25(43.8)$ \\
\hline It was not helpful in reducing their \\
anxiety & $29(50.9)$ \\
\hline & \\
\hline
\end{tabular}

\section{Discussion}

Although the causes of orofacial clefts among most infants are unknown, it is thought to be multifactorial due to combination of genes and environmental factors (smoking mother etc) or certain medications. Studies have shown that Women who smoke during pregnancy ${ }^{10}$ and women who used certain medicines to treat epilepsy (Topiramate, Valproate) during the first trimester of pregnancy ${ }^{11}$ have an increased risk of having a baby with cleft lip with or without cleft palate, compared to women who didn't smoke and take these medicines. In the current study, majority $(71.9 \%)$ of the participants thought that the cause of CLCP is multifactorial and $26.3 \%$ of them thought CLCP to be genetic.
The incidence of CLCP is about 1 out of every 500 to 800 live births in India. ${ }^{12}$ Although data from Nepal isn't available, many cases visit $\mathrm{KCH}$ as this is the only tertiary level children hospital of the country. The prevalence of cleft patient visiting the hospital per month for variety of problems in this survey was approximately 0-5 infants. Most common age group that approached hospital in need of treatment with CLCP was in neonatal period (43.9\%) followed by age of 1-3 months (29.8\%). Among different causes of hospital visit, $57.9 \%$ of the doctors said that difficulty in feeding and swallowing was the most common cause. Other causes of hospital visit were regurgitation and aspiration $(22.8 \%)$, failure to thrive $(8.8 \%)$, esthetics etc. 
A number of other studies have also reported that slow weight gain in infants with cleft palate, especially in the first few months of life was the major cause of hospital visit. ${ }^{6}$ In a study done by Sivanagini et al, parents also bother about the feeding disabilities and $70 \%$ of patient's were brought to the clinic at around 15-45 days. ${ }^{9}$

Majority of the doctors (73.7\%) acknowledged the need of multidisciplinary approach for the treatment of these patients in current study. These patients require a multidisciplinary treatment with the team including ENT Surgeon, Genetic scientist, plastic and oral surgeon, orthodontist, prosthodontist, pediatric dentist, ophthalmologist, psychiatrist, speech therapist, nursing support, and social worker. ${ }^{13}$ $84.2 \%$ of the doctors thought that the ultimate goal of management of child with cleft palate is to have normal speech, maxillofacial growth and hearing. The early surgical repair of the cleft palate is associated with good cosmesis, better feeding, adequate velo-pharyngeal competence, growth and good speech and hearing development. The treatment of cleft lip and palate extends over the infancy, childhood, and adolescence of individuals who are born with this condition with multiple surgeries throughout these years. ${ }^{14}$ Ideally, cleft palate repair must be completed before the age of 2 years. In our study, $45.6 \%$ of the doctors thought that ideal age for soft palate repair in two stage closure was 9-12 months whereas $29.8 \%$ said that it should be done in 3-6 months. For hard palate repair in two stage closure, $49.1 \%$ of the doctors thought that ideal age for was 15-18 months whereas $36.8 \%$ said that it should be done in 10 months of age.

Although the definitive treatment of CLCP patient is surgical repair, optimising the child's health before surgery is of utmost importance. Inability to feed, slow weight gain and recurrent aspiration are of major concern. Patients should be explained about the treatment cycle and stepwise procedure which helps in consulting a proper clinician at that particular time. Before surgery, a palate defect has to be obturated well so that the negative pressure required for suckling is obtained and the patient is able to breastfeed. ${ }^{15}$ Interventions reported for infants with cleft conditions included special feeding equipments (specialised teats and nipples, Cup/ spoon and disposable syringe feeding, feeding plate) and feeding technique (Enlargement, Stimulate, Swallow, Rest [ESSR] method). ${ }^{16}$ Randomized controlled trial comparing modified feeding equipment (compressible bottle and NUK orthodontic nipple) lead to significantly greater weight gain and head circumference in nonsyndromic infants with clefts. ${ }^{17}$ This should be started as early as possible to help them maintain normal weight and to prevent regurgitation so that they can undergo surgery at the recommended time. ${ }^{18,19}$ The feeding plate obturator is a prosthetic work which is usually fabricated by a prosthodontist or general dentist or a plastic surgeon. ${ }^{20}$ which creates a rigid platform on which a baby can press the nipple to create sufficient negative pressure that allows for adequate suckling of milk. In the current study, none of the participants thought Prosthodontist as concerned clinicians in the team for multidisciplinary treatment and only $15.8 \%$ of participants primarily sent cleft patient to Prosthodontists for management.

Our study revealed that $49.1 \%$ of the participants suggested feeding plate oburator as the best way to feed a cleft patient on discharge from hospital and 7\% suggested modified nipples and Nasogastric/Orogastric tube feeding. Feeding plate obturator facilitates feeding by enhancing baby's suckling effort ${ }^{21}$, reduces nasal regurgitation and the incidence of choking, and prevents the tongue from entering the defect so that the spontaneous growth of palatal shelves towards the midline occurs without any interference. 
Despite the prevalence of prenatal diagnosis, many parents are unprepared for the birth of a child with cleft lip and palate. ${ }^{22}$ They must cope with feelings of shock, loss, grief and worry as they try to accomplish important tasks such as learning to feed their infant and seeking information about long-term care. ${ }^{23}$ Each time a child is hospitalized, regardless of the length of the hospitalization or seriousness of the procedure, the child and family must cope with a variety of stressors that vary based on family make-up and psychological functioning. Ideally, feeding interventions should reduce stress experienced by the family and infant, promote growth and development, and facilitate a normal feeding pattern. ${ }^{16} 49.1 \%$ of partcipants in our study thought that feeding plate reduced the anxiety levels of mothers during feeding. However, most participants did not refer/advise the cleft patient for fabrication of feeding plate obturator, even if they advised, they didn't know the frequency of replacement and also majority of them had never helped the dentist in making the impression of cleft palate for feeding plate fabrication. In their clinical practice, three fourth of paticipants $(70.2 \%)$ had never seen a patient with feeding plate obturator.

\section{Limitation}

As this study was done in a single hospital, findings can't be generalised to all the medical doctors throughout the country. Further studies should be carried out to find the knowledge gap about CLCP among the primary care physicians.

\section{Conclusion}

The management of orofacial clefts represents a logistical challenge for the general medical profession. Medical doctors working in $\mathrm{KCH}$ had good knowledge regarding cleft and its management through multidisciplinary approach. They were aware about the use of feeding plate obturator as treatment option but in clinical practice many of them haven't seen the patients with feeding plate obturator and also they dont advise for feeding plate obturator . This study revealed that there is low exposure regarding the feeding plate obturator among medical doctors which needs to be reinforced through meaningful continuing education and training programs to deliver better quality care for CLCP infants.

\section{Acknowledgements}

The authors would like to extend sincere thanks to all the medical doctors of Kanti Children's Hospital who participated in this study and Dr Anju Khapung for her help with statistical analysis.

\section{References}

1. Savion I, Huband ML. A feeding obturator for a preterm baby with Pierre Robin sequence. $J$ Prosthet Dent 2005;93:197-200.

2. Goyal M, Chopra R, Bansal K, Marwaha M. Role of obturators and other feeding interventions in patients with cleft lip and palate: a review. European Arch Paed Dent 2014;15:1-9.

3. Peterson-Falzone SJ. Optimal age for palatoplasty to facilitate normal speech development: what is the evidence? Cleft lip and palate: Springer; 2013. p. 787-802.

4. Goldberg W, Ferguson F, Miles RJ. Successful use of a feeding obturator for an infant with a cleft palate. Spec Care Dentist 1988;8:86-9.

5. Clarren SK, Anderson B, Wolf LS. Feeding infants with cleft lip, cleft palate, or cleft lip and palate. Cleft Palate J 1987;24:244-9.

6. Avedian LV, Ruberg RL. Impaired weight gain in cleft palate infants. Cleft Palate J 1980;17:246.

7. Lee J, Nunn J, Wright C. Height and weight achievement in cleft lip and palate. Arch Dis Child 1996;75:327-9.

8. Narendra R, Sashi Purna C, Reddy S, Simhachalam Reddy N, Sesha Reddy P, Rajendra Prasad B. Feeding obturator-a presurgical prosthetic aid for infants with cleft lip and palate-clinical report. Ann Essences Dent 2013;5:1-5. 
9. Sivanagini Y, Ganapathy D, Jain AR. Knowledge, attitude, and practice of feeding plate obturators among dental practitioners. Drug Invent Today 2018;10:1957-64.

10. Honein MA, Rasmussen SA, Reefhuis J, Romitti PA, Lammer EJ, Sun L, et al. Maternal smoking and environmental tobacco smoke exposure and the risk of orofacial clefts. Epidemiology 2007:226-33.

11. Margulis AV, Mitchell AA, Gilboa SM, Werler MM, Mittleman MA, Glynn RJ, et al. Use of topiramate in pregnancy and risk of oral clefts. Am J Obstet Gynecol 2012;207:405-7.

12. Sharma R. Birth defects in India: Hidden truth, need for urgent attention. Indian J Hum Genet 2013;19:125-9.

13. Turvey TA, Vig K, Moriarty J, Hoke J. Delayed bone grafting in the cleft maxilla and palate: a retrospective multidisciplinary analysis. $\mathrm{Am} \mathrm{J}$ Orthod 1984;86:244-56.

14. Kapp-Simon KA. Psychological issues in cleft lip and palate. Clin Plast Surg 2004;31:347-52.

15. Karayazgan B, Gunay Y, Gurbuzer B, Erkan M, Atay A. A preoperative appliance for a newborn with cleft palate. Cleft Palate Craniofac $J$ 2009;46:53-7.

16. Reid J. A review of feeding interventions for infants with cleft palate. Cleft Palate Craniofac $J$ 2004;41:268-78.
17. Shaw WC, Bannister RP, Roberts CT. Assisted feeding is more reliable for infants with clefts - a randomized trial. Cleft Palate Craniofac J 1999;36:262-8.

18. Kapoor D, Garg D. Immediate rehabilitation with feeding appliance of a three day old neonate with cleft lip and palate-a case report. $J$ Coll Med Sci Nepal 2017;13:293-5.

19. Rathee M. Single Visit Feeding Appliance for 1-day-old Neonate with Cleft Palate Using Safe Dental Putty-Gauze Hybrid Impression Technique for Maxillary Impression. J Surg Tech Case Rep 2015;7:7-11.

20. Cooper-Brown L, Copeland S, Dailey S, Downey D, Petersen MC, Stimson C, et al. Feeding and swallowing dysfunction in genetic syndromes. Dev Disabil Res Rev 2008;14:14757.

21. Crossman K. Breastfeeding a baby with a cleft palate: a case report. J Hum Lact 1998;14:4750.

22. Johnson N, Sandy JR. Prenatal diagnosis of cleft lip and palate. Cleft Palate Craniofac $J$ 2003;40:186-9.

23. Endriga MC, Kapp-Simon KA. Psychological issues in craniofacial care: state of the art. Cleft Palate Craniofac J 1999;36:3-11. 